\title{
Sizing Study of Second Life Li-ion Batteries for Enhancing Renewable Energy Grid Integration
}

\author{
Andoni Saez-de-Ibarra, Egoitz Martinez-Laserna, Daniel-Ioan Stroe, \\ Maciej Swierczynski, and Pedro Rodriguez, Fellow, IEEE
}

\begin{abstract}
Renewable power plants must comply with certain codes and requirements to be connected to the grid, being the ramp-rate compliance one of the most challenging requirements, especially for photovoltaic or wind energy generation plants. Battery-based energy storage systems represent a promising solution due to the fast dynamics of electrochemical storage systems, besides their scalability and flexibility. However, large-scale battery energy storage systems are still too expensive to be a mass market solution for the renewable energy resources integration. Thus, in order to make battery investment economically viable, the use of second life batteries is investigated in the paper. This paper proposes a method to determine the optimal sizing of a second life battery energy storage system (SLBESS). SLBESS performance is also validated and, as an ultimate step, the power exchanged with the batteries is calculated during one-year operation. The power profile obtained is further used to define the cycling patterns for laboratory testing of second life batteries and to study their ageing evolution when used for the power smoothing renewable integration application. Real photovoltaic energy generation data from a Spanish plant were used for the study.
\end{abstract}

Index Terms-Batteries, energy storage, optimization, second use, solar energy.

\section{NOMENCLATURE}

$C_{\text {bat }}$
$C_{\text {batglobal }}(t)$
$C_{\text {ref }}(t)$
$E_{\text {bat }}(t)$

meas $_{\text {freq }}$

$\mathrm{OCV}$

Battery nominal capacity.

Global battery nominal capacity.

Battery instantaneous reference capacity.

Second life battery energy storage system (SLBESS) instantaneous energy.

Sampling frequency.

Open circuit voltage of the cell at a certain state of charge (SOC).

Paper 2015-SECSC-1072.R1, presented at the 2015 IEEE Energy Conversion Congress and Exposition, Montreal, QC, Canada, Sep. 20-24, and approved for publication in the IEEE TRANSACTIONS ON INDUSTRY APPLICATIONS by the Sustainable Energy Conversion Systems Committee of the IEEE Industry Applications Society. This work was supported by the European Union through the NMP.2013-1 Batteries2020 Project under Grant GC.NMP.2013-1 /GA nº 608936. Andoni Saez de Ibarra and Egoitz Martinez Laserna contributed equally to the development of this paper.

A. Saez-de-Ibara and E. Martinez-Laserna are with the IK4-IKERLAN Technology Research Centre, Arrasate-Mondragón 20500, Spain (e-mail: asaezdeibarra@ikerlan.es; emartinez@ikerlan.es).

D.-I. Stroe and M. Swierczynski are with the Department of Energy Technology, Aalborg University, Aalborg 9220, Denmark (e-mail: dis@et.aau.dk; mas@et.aau.dk).

P. Rodriguez is with Abengoa Research, Seville 72178, Spain (e-mail: pedro.rodriguez@se.abb.com).
$P_{\text {bat }}(t)$
$P_{\text {cell }}$
$P_{\text {Plant }}(t)$
$P_{\text {PV }}(t)$
RRC
$R_{\text {in }}$
RR_limit $_{\text {SOC }}$
SOni $_{\text {SOC }}$ max
SOC $_{\text {min }}$
SOH $_{\text {ini }}$
SOH $_{\text {min }}$

Sum $_{\text {disch }}$
$V_{\text {min }}$
$Z$

I NTEGRATING large renewable energy sources (RES) power plants into the grid presents both economic and environmental benefits [1], [2]. Meanwhile, it also raises technical challenges for the grid stability and integrity due to the highly variable and intermittent characteristic of RES.

A solution to mitigate the effects of RES high variability and enhance the stability of grids with high penetration levels of renewable power plants is to use battery energy storage systems (BESSs) connected to the grid at the same point as the RES [3]. The BESSs have a response time in the range of milliseconds [4], [5] and are able to compensate in real time the high variability of the renewable resource [6]-[8]. These systems are able to smooth the power output of the plant by reacting to the high variations in power generation and to deal with these variations by operating in charging/discharging mode in order to keep the output power ramp rate of the plant inside admissible values [4].

Before being allowed to connect and inject power into the grid, all power plants need to pass compliance tests [5]. These tests impose constraints related to the operation of the plant and their response to different grid events. Moreover, compliance tests are compulsory for the grid connection of the plants. While passing the tests add no economic benefits, the violation of the stated limits will bring penalties to the plant operator. In order to comply with these tests, the solution requiring the smaller initial investment is the best suited for this application. Several alternatives such as diesel generators, natural gas turbines, or electrochemical energy storage can be used. For the particular case of the lithium-ion (Li-ion) battery energy storage 


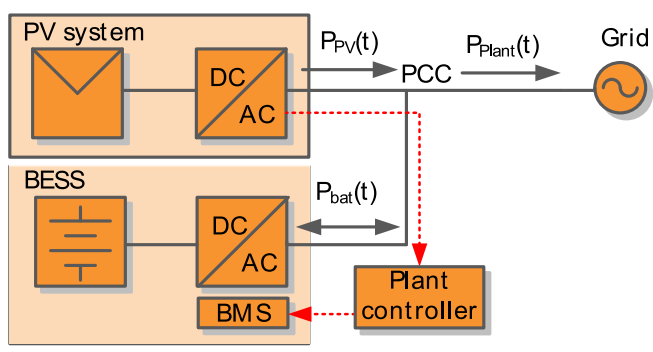

Fig. 1. Block diagram of PV variability output power smoothing application with BESS.

considered in this study, this can be achieved, for example, by optimizing the size of the battery and by reducing the initial investment cost of the storage system [9]-[18].

This paper focuses on the operation of a Li-ion-based BESS capable of limiting the variability of a photovoltaic (PV) power plant. In this way, three main goals are covered: 1) operation and control of the BESS; 2) optimization of the BESS size; and 3) definition of the cycling patterns for laboratory testing of Li-ion batteries. The work presented in this paper is part of the European project Batteries 2020 [19] that proposes the use of second life (SL) Li-ion batteries (retired from their first life automotive service) for a BESS (SLBESS), which provides the RES smoothing application. SL batteries are considered to be significantly cheaper than new Li-ion batteries while still retaining most of the performance capabilities of fresh $\mathrm{Li}$-ion batteries [20]-[23]. Thereby, the major driver for using SL batteries is the possibility of reducing costs and minimizing the environmental impact, by avoiding the manufacturing of new Li-ion batteries to cover the same application. In order to obtain realistic results, this paper considers an initial state of health (SOH) for the SL application of $80 \%$ of the initial BESS capacity [23]-[25]. The capacity decay trend and other performance characteristics of SL batteries have also been considered.

The rest of the paper is structured as follows. Section II presents the requirements of the power variability smoothing service for PV plants connecting to the grid, Section III presents the proposed algorithm for controlling the SLBESS in order to provide the service. Section IV presents the methodology for rating the SLBESS according to the considered application. Section V presents and discusses the simulation results. Section VI summarizes the battery test profile definition, and Section VI presents the conclusion derived from the work.

\section{SLBESS POWER VARIABILITY SMOOTHING}

The block diagram of the system under study for power variability smoothing is presented in Fig. 1. The plant controller is responsible for measuring the current value of the PV output power $\left(P_{\mathrm{PV}}\right)$ and controls the SLBESS power exchange $\left(P_{\mathrm{bat}}\right)$ in order to maintain the plant's output power $\left(P_{\text {Plant }}\right)$ between admissible limits, according to

$$
P_{\text {Plant }}(t)=P_{\mathrm{PV}}(t)+P_{\text {bat }}(t) .
$$

Different system operators have different requirements for connecting RES power plants to the grid. This paper focuses on the RES variability smoothing and ramp-rate limits imposed for the power plants grid connection. A ramp-rate limit considered for many studies is the one defined by the Puerto Rico Electric Power Authority (PREPA) codes [26] as a maximum value of $10 \% / \mathrm{min}$. for the ramp rates [4]. In addition, in [8], the "Asociación de Productores de Energía Renovable" (APER, Renewable Energy Producers Association) has defined compliance tests for integrating RES power plants into the grid and to facilitate the interaction between the PREPA and the companies developing and operating the plants.

Of special interest for this paper is the ramp-rate compliance (RRC) as it is defined by the APER: the facility will be considered to be noncompliant and a curtailment penalty will be applied to the plant if the RRC is less than $98.5 \%$ during each full week. The penalty will consist of a reduction in the contracted capacity of the plant for the next week [26].

For a given time interval, the total number of compliant scans may be expressed as a percentage of all scans, which is known as RRC [8]

$$
\mathrm{RRC}=100 \%-\frac{(\# \text { of scans in violation of } \mathrm{RR})}{(\# \text { of scans while facility is generating })} .
$$

The aforementioned criterion is used at the end of the paper to validate the results obtained based on the proposed rating methodology and power smoothing algorithm. Moreover, the criterion is also included in the developed battery energy management algorithm, presented in the following section.

\section{BAtTery Energy MANAGement Algorithm}

The first part of the process of assessing the required rating of the SLBESS is to determine the control algorithm that controls the battery for providing the variability smoothing service [27]-[29].

In this paper, based on the least-squares estimator (LSE) described in [5], a mixed least-squares estimator ramp-rate compliant (MLSERRC) algorithm is developed to smooth the plant output power, $P_{\text {Plant }}$. The idea behind this algorithm is to include the LSE based on a parabolic estimation instead of a linear estimation (LSE) complemented with the RRC limit.

This algorithm executes at each sample time the process presented in the diagram of Fig. 2(a). It starts updating the evaluation time horizon. As it is a least-squares estimator, the time horizon must be fixed and updated at every time step. Then, the new PV power value $\left(P_{\mathrm{PV}}(t)\right)$ is read to allow updating the least-squares approximation. At this moment, a parabolic least-squares estimation of the past time horizon's fixed values is computed to obtain the current value of the plant's output power, $P_{\text {Plant }}(t)$. Based on this data, the difference between the last two values of the plant output power is calculated to determine in the next step if this difference is lower than the ramp-rate limit. If this difference is lower than the limit, the considered value of the plant output power is the one obtained from the parabolic least-squares estimation. On the contrary, if the difference exceeds the ramp-rate limit, the $P_{\text {Plant }}(t)$ value is limited by the RRC. Therefore, considering the instantaneous plant output power and the PV power, the storage system power 


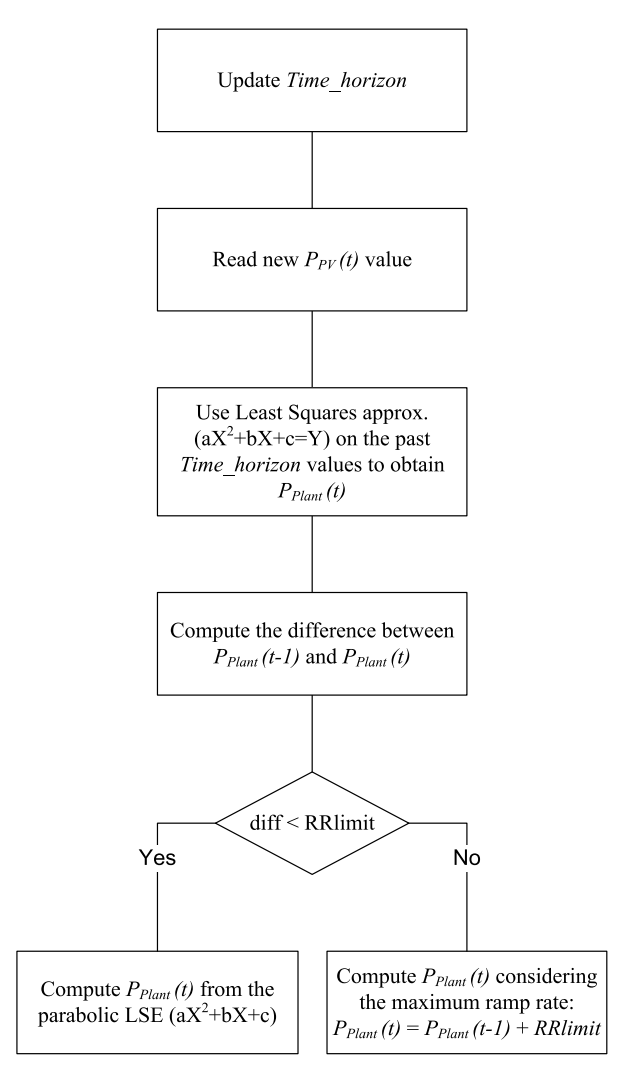

(a)

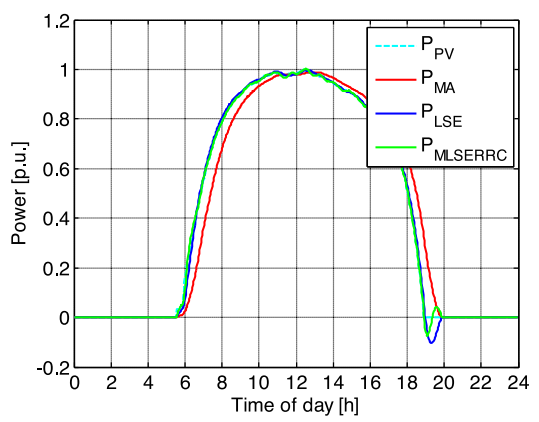

(b)

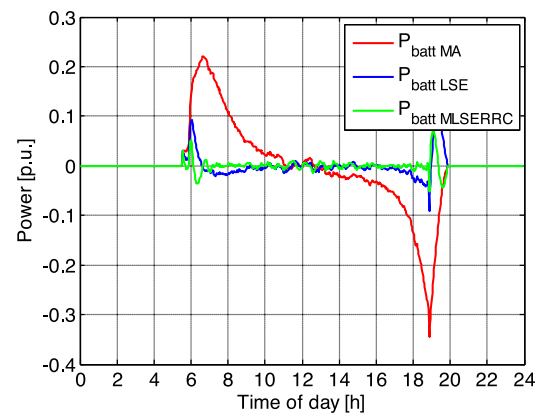

(d)

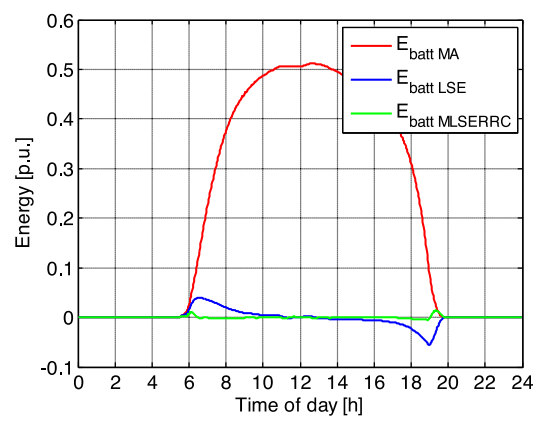

(f)

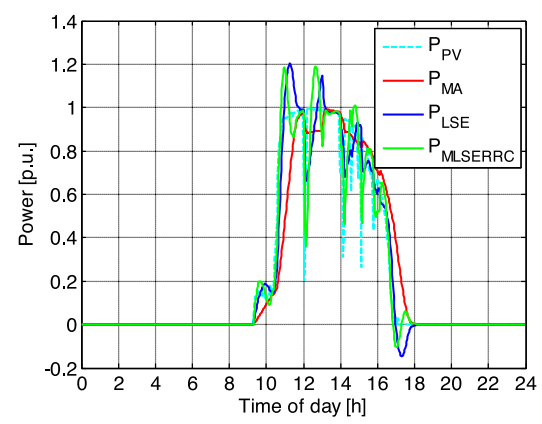

(c)

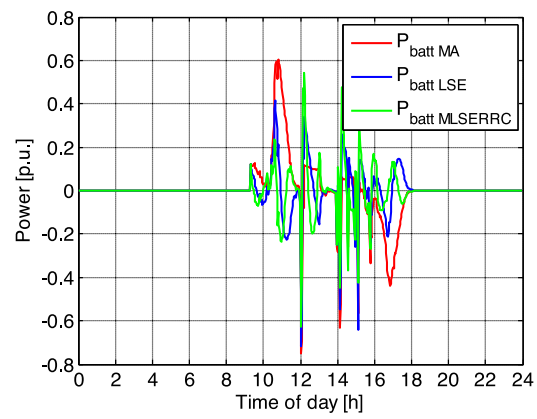

(e)

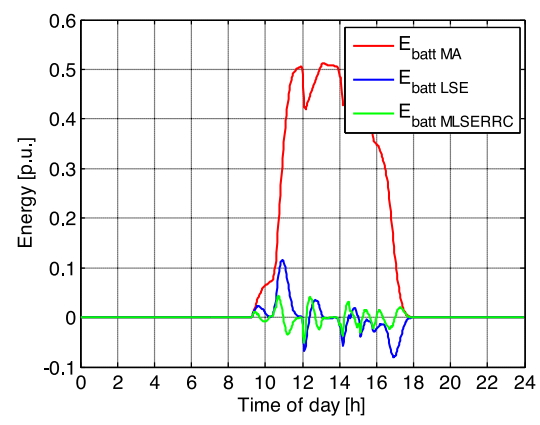

(g)

Fig. 2. SLBESS smoothing operation algorithm: (a) Algorithm's diagram, PV plant output power for (b) sunny day; (c) high irradiance variable day, battery power profile; (d) sunny day; (e) high irradiance variable day, battery energy profile; (f) sunny day; and (g) high irradiance variable day.

value can be determined, and from this value, the energy requirements can also be calculated, as shown in Fig. 2.

The MLSERRC algorithm is used as it returns better results than the least-squares estimator based on an LSE and also than the moving average (MA) filter algorithm. Compared to the MA and LSE algorithms, the use of the MLSERRC algorithm reduces the size of the SLBESS required to provide the output power smoothing service in addition to providing the RRC service. The compared operation results between the use of the MA, LSE, and MLSERRC algorithms are presented in Fig. 2 for two types of days: sunny (b, $d$, and $f$ ) and for a day with highly variable irradiance (c, e, and g).

Fig. 2(b) presents the PV output power $\left(P_{\mathrm{PV}}\right)$, the plant's smoothed output power when using the MA filter $\left(P_{\mathrm{MA}}\right)$, when using the LSE filter $\left(P_{\mathrm{LSE}}\right)$, and when using the MLSERRC algorithm ( $\left.P_{\text {MLSERRC }}\right)$ under the same weather conditions. For providing these plant output power characteristics, the requirements for the storage system in terms of power and energy are shown in Fig. 2(d) and (f), respectively. As it is presented in
Fig. 2, both power and energy requirements obtained for the MLSERRC algorithm are lower than the ones obtained for the LSE and MA filters.

Similar conclusions can be drawn by analyzing the cloudy and the high-irradiance variable day figures, [see Fig. 2(c), (e), and (g)], where the MLSERRC algorithm is again the most performant, especially in the case of SLBESS energy requirement.

As a summary, for both types of days, the use of the MLSERRC algorithm shows better results than LSE filter and MA filter, respectively. This translates into smaller battery capacity needed and smaller power converter size needed for providing the power smoothing service and assuring RRC, at the same time.

\section{OPTIMAL SizING OF THE SLBESS}

For determining the optimal rating of the SLBESS, measurements taken from a real PV power plant over one-year interval 
TABLE I

DESIGN VARIABLES

\begin{tabular}{ll}
\hline \hline Design Variable & Description \\
\hline$C_{\text {bat }}$ & Battery nominal capacity \\
$C_{\text {ref }}(t)$ & Battery instantaneous reference capacity \\
$P_{\text {bat }}(t)$ & Battery instantaneous power \\
$E_{\text {bat }}(t)$ & Battery instantaneous energy \\
\hline \hline
\end{tabular}

were used. These values are normalized according to the maximum output power recorded in the measurement vector.

The optimal sizing process is separated in two main steps, comprising two different optimization processes. Nevertheless, both optimizations are carried out by means of a linear programming (LP) optimization. The LP optimization was formulated as

$$
\min _{x} c^{T} x \text { such that }\left\{\begin{array}{l}
A \cdot x \leq b \\
A_{\mathrm{eq}} \cdot x=b_{\mathrm{eq}}, . \\
l b \leq x \leq u b .
\end{array}\right.
$$

The first step (or the first optimization process) calculates the optimal rating of the battery for each day of the year, as well as the power exchange profile. The second step (or the second optimization process) calculates the global optimal size of the SLBESS considering the optimal values calculated for each day (obtained in the first step). After the rating of the battery is determined, the proposed MLSERRC algorithm will be used to validate the results.

\section{A. First Step: Daily Optimization}

The problem of optimally sizing the storage system is closely connected to the operation algorithm of the SLBESS. For that reason, in the formulation of the optimization process, the operation of the battery is also optimized, assuming perfectly known conditions-similar to the operation of a model predictive control with perfect predictions.

For the daily optimization problem, the following design variables are used, as specified in Table I. These design variables compose the vector $x$ of the linear optimization presented in (3).

The use of these design variables will provide the optimal battery nominal capacity for the beginning of the SL application; this represents the necessary capacity of the SLBESS to be used in the output power smoothing application. In addition, three series (vectors) of data are also generated: these are the battery instantaneous reference capacity, which due to degradation will decay in time, the battery instantaneous power, and the battery instantaneous energy.

The last two design variables, $P_{\mathrm{bat}}$ and $E_{\mathrm{bat}}$, as part of the optimization result, are describing the operation of the battery for the current simulation scenario. This result reflects the optimal operation mode of the battery, considering all the input signals (the solar generation values) a priori known. Based on this power exchange $\left(P_{\text {bat }}\right)$ and capacity $\left(C_{\text {bat }}\right)$, the energy level of the battery $\left(E_{\mathrm{bat}}\right)$ is also provided, for each moment of the simulation interval.

The objective of the optimization process is to minimize the required capacity of the SLBESS as presented in (4) for the PV power plant ramp reduction service

$$
\min _{C_{\text {bat }}} C_{\text {bat }} .
$$

In order to ensure the proper functioning of the optimization algorithm, and with the objectives of setting the operation boundaries of the several elements implied in the diagram shown in Fig. 1, a set of constraints has been defined. Considering the ramp limiting objective of the SLBESS, a double inequality was defined

$$
\begin{aligned}
& P_{\mathrm{PV}}(t)-P_{\mathrm{PV}}(t-1)+P_{\text {bat }}(t)-P_{\text {bat }}(t-1) \leq \mathrm{RR} \_ \text {limit } \\
& -P_{\mathrm{PV}}(t)+P_{\mathrm{PV}}(t-1)-P_{\text {bat }}(t)+P_{\text {bat }}(t-1) \leq \mathrm{RR} \_ \text {limit }
\end{aligned}
$$

where $P_{\mathrm{PV}}$ [p.u.] is the output power of the PV plant, $P_{\mathrm{bat}}$ [p.u.] is the output power provided by the SLBESS, and $t$ is the time instant of the day considered. In a similar way, (7) and (8) ensure that the battery operates within the SOC limits defined

$$
\begin{aligned}
& -\frac{1}{\text { meas }_{\text {freq }}} P_{\text {bat }}(t)+E_{\text {bat }}(t)-\mathrm{SOC}_{\text {max }} \cdot C_{\text {ref }}(t) \leq 0 \\
& \frac{1}{\text { meas }_{\text {freq }}} P_{\text {bat }}(t)-E_{\text {bat }}(t)+\mathrm{SOC}_{\text {min }} \cdot C_{\text {ref }}(t) \leq 0
\end{aligned}
$$

where $P_{\mathrm{bat}}$ [p.u.] is the power exchanged with the battery, $E_{\mathrm{bat}}$ [p.u.] is the battery instantaneous energy, $\mathrm{SOC}_{\max }[\%]$ and $\mathrm{SOC}_{\min }[\%]$ are the maximum and minimum allowed operation State of Charge (SOC), respectively, and $C_{\text {ref }}$ [p.u.] is the capacity reference at each sample of time, which takes into account the battery degradation effect over the initial installed capacity rating $C_{\text {bat }}$ [p.u.]. Additionally, measfreq $\left[\mathrm{h}^{-1}\right]$ accounts for the measurement frequency or the sampling time considered that in this case is $2 \mathrm{~min}$.

Further battery operation restrictions include battery $\mathrm{SOH}$ limits, as it can be observed in (9) and (10). According to these two equations, the instantaneous capacity $C_{\text {ref }}$ at each sample time-which takes into account battery degradation - must be within the maximum $\mathrm{SOH}$, which is its initial $\mathrm{SOH}_{\mathrm{ini}}[\%]$ and minimum $\mathrm{SOH}_{\min }[\%]$ limits established

$$
\begin{aligned}
& \mathrm{SOH}_{\text {min }} \cdot C_{\text {bat }}-C_{\text {ref }}(t) \leq 0 \\
& -\mathrm{SOH}_{\text {ini }} \cdot C_{\text {bat }}+C_{\text {ref }}(t) \leq 0 .
\end{aligned}
$$

The instantaneous capacity $C_{\text {ref }}$ is calculated according to (3) and (12). Equation (3) ensures that a capacity increase from one instant to the next is never possible, whereas (12) calculates the capacity decay according to the energy throughput between two consecutive time instants and the constant degradation factor $Z$ [-] as defined by Riffonneau in [30]

$$
\begin{aligned}
& C_{\text {ref }}(t)-C_{\text {ref }}(t-\Delta t) \leq 0 \\
& C_{\text {ref }}(t)-C_{\text {ref }}(t-\Delta t)-Z \cdot\left[E_{\text {bat }}(t-\Delta t)-E_{\text {bat }}(t)\right] \leq 0 .
\end{aligned}
$$


The initial condition of both equations is calculated as

$$
\begin{aligned}
& C_{\text {ref }}(1)-\mathrm{SOH}_{\text {ini }} \cdot C_{\text {bat }} \leq 0 \\
& -Z \cdot\left[E_{\text {bat }}(1)-\mathrm{SOH}_{\text {ini }} \cdot \mathrm{SOC}_{\text {ini }} \cdot C_{\text {bat }}\right] \leq 0 .
\end{aligned}
$$

Equation (15) restricts the power flow of the PV plant plus SLBESS, so that no negative resultant power output is allowed; this ensures that the power is only injected into the grid, and that no grid power absorption is allowed

$$
-P_{\mathrm{bat}}+P_{\mathrm{PV}}(t) \leq 0 .
$$

These inequalities complete the matrix $A$ and the vector $b$ of the optimization problem is presented in (3). Each row of the matrix $A$ and vector $b$ is composed of the following inequalities: (5)-(11) with the initial conditions defined by (12) and (13) also with the initial conditions in (14) and (15), respectively.

Finally, taking into account the equality constraints, the battery operation equation is defined, so that the power demanded to the battery during a certain period of time equals the change in the instantaneous energy available in the battery at the beginning and the end of that period of time

$$
E_{\mathrm{bat}}(t)-E_{\mathrm{bat}}(t-\Delta t)-P_{\mathrm{bat}}(t) \cdot \Delta t=0 .
$$

The initial condition of (16) is modeled as

$$
E_{\text {bat }}(1)-\mathrm{SOH}_{\mathrm{ini}} \cdot \mathrm{SOC}_{\mathrm{ini}} \cdot C_{\mathrm{bat}}-P_{\text {bat }}(1) \cdot \Delta t=0 .
$$

These constraints are included in the matrix $A_{\mathrm{eq}}$ and vector $b_{\text {eq }}$ of the optimization problem defined in (3).

The correct assignment of some of these variables entails knowing some of the most relevant battery performance characteristics. Considering that in this case, the scope of the sizing process is to obtain representative power profiles and cycling patterns for a later battery testing, it is difficult to provide precise values for some of these variables.

In this way, the maximum and minimum $\mathrm{SOH}$ limits $\left(\mathrm{SOH}_{\mathrm{ini}}\right.$ and $\mathrm{SOH}_{\mathrm{min}}$, respectively) have been assigned according to typical values reported in the literature for SL batteries. According to the industry, the most widespread criterion is that electric vehicle batteries are retired from their automotive use when they reach $80 \%$ of the nominal capacity [23]-[25]. Thereby, once transferred to the SL, the initial $\mathrm{SOH}$ available would be $\mathrm{SOH}_{\text {ini }}=80 \%$. In addition, the $\mathrm{SOH}$ value at which the batteries would be retired from the SL use has been established as $\mathrm{SOH}_{\min }=64 \%$ of the nominal battery capacity. This supposes that an additional $80 \%$ of the battery capacity initially available in the $\mathrm{SL}\left(\mathrm{SOH}_{\mathrm{ini}}\right)$ is only consumed during the $\mathrm{SL}$ use. This SL battery retirement criterion was contrasted with the literature, and it is slightly above the $50 \%$ (with respect to the nominal capacity) retirement criterion established by Neubauer and Pesaran in [23].

Similarly, determining the BESS maximum and minimum power capabilities implies assuming certain hypotheses that will not be validated until the batteries are subjected to real testing. However, considering batteries' pulse power capabilities, measured by means of pulse power characterization testing at the beginning of life (BOL) of the cells considered in this analysis

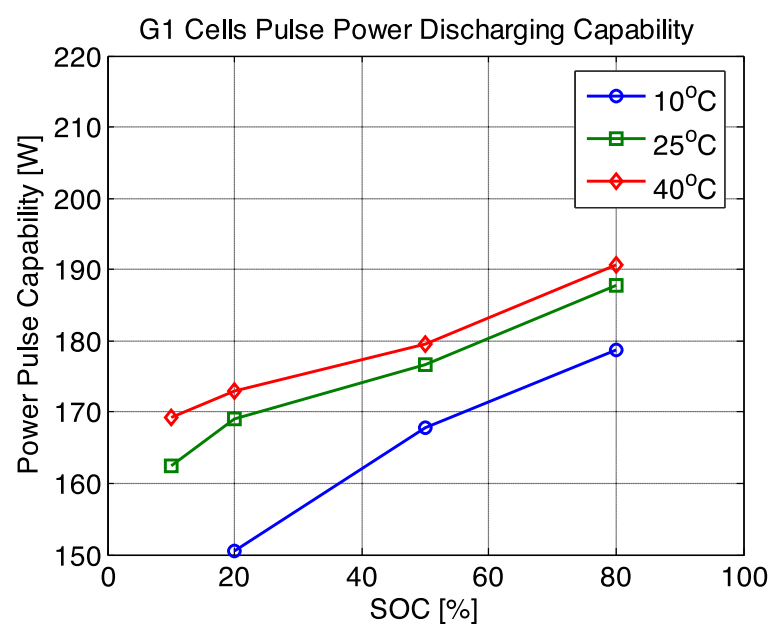

(a)

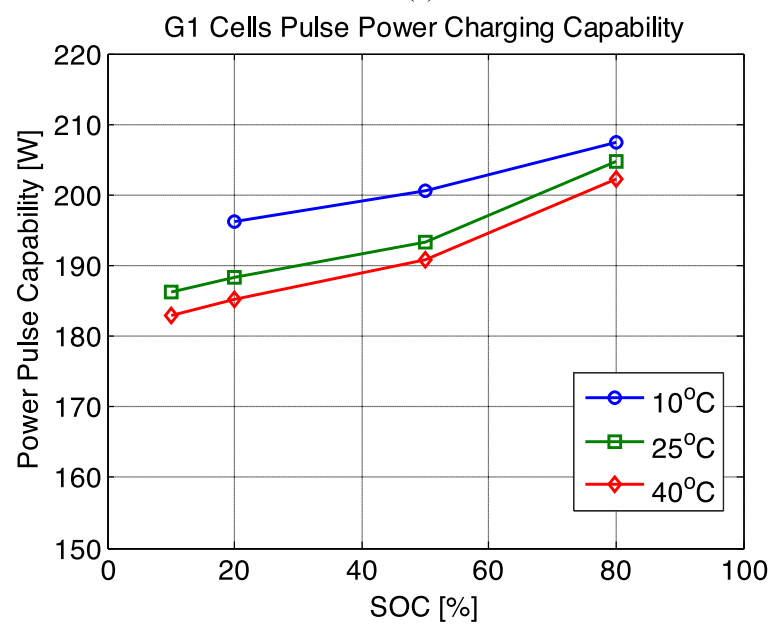

(b)

Fig. 3. Battery discharging (a) and charging (b) pulse power capabilities measured at BOL for different temperatures.

(presented in Fig. 3), it was decided to establish an operating range from $\mathrm{SOC}_{\min }=20 \%$ to $\mathrm{SOC}_{\max }=80 \%$. The cells used for this analysis are 20 Ah high-energy NMC-based commercial cells. These cells will be later subjected to SL testing with the power profiles obtained from the results of the sizing study presented in this paper.

As shown in Fig. 3, the power capabilities of such cells, calculated according to (18) are considerably lowered below $20 \%$ SOC [31]. In absolute values, this will be even more evident as cells degrade. This paper models the SOC referring to the current capacity of the battery and not with the initial one. On the other hand, it was also considered that the useful life of the SL batteries will be enhanced by limiting the operation range to a maximum $60 \%$ cycle depth, which leads to the mentioned 20 $80 \%$ SOC interval. Even though the operating limits established may seem conservative taking BOL characteristics into account, it is expected that cell power and energy capabilities will be considerably lowered before being used in the considered SL 
application

$$
P=V_{\min } \cdot \frac{\left(\mathrm{OCV}-V_{\mathrm{min}}\right)}{R_{\mathrm{in}}}
$$

where $P[\mathrm{~W}]$ is the charging/discharging power capability of the cell, $V_{\min }[\mathrm{V}]$ is the voltage of the cell at the end of a $10 \mathrm{~s}$ charge/discharge pulse, OCV [V] is the open circuit voltage of the cell at a certain SOC, and $R_{\text {in }}$ is the charge/discharge internal resistance measured at the considered conditions (temperature and SOC).

On the other hand, determining an accurate capacity fade coefficient $(Z)$ requires inevitable cell testing and a battery ageing model. Thus, considering the particularity of the case here explained, this coefficient needs to be somehow established before the cells are subjected to ageing tests. It was decided to use the capacity fade coefficient calculated for the first life ageing, assuming that the ageing mechanisms governing cell performance in the first life will continue being the same along the SL. However, this assumption needs to be validated after SL battery testing.

As a result, the daily optimal size of the SLBESS is obtained. Depending on the conditions of each day, these values can differ significantly from cases where the use of the battery is not necessary, to days that require a 0.06 (p.u.) of battery storage, as shown in Fig. 5.

An initial assumption that the battery SOC has the same initial value at the beginning of each day can be justified by the fact that the battery's controller can easily bring the battery to this SOC value during the day when power is available from the PV system. The battery enters an "initial SOC" mode of operation and charges from the PV or discharges into the grid the energy difference until $\mathrm{SOC}_{\mathrm{ini}}$ is reached. The described optimization process is developed in MATLAB.

\section{B. Second Step: Global Optimization}

Once the daily optimal size of the SLBESS is obtained, another linear optimization is carried out to calculate the global optimal size of the SLBESS, in order to respect the constraints imposed by the individual solutions for each day over the whole year.

In this case, there is a single design variable, that is the battery nominal capacity, $C_{\text {batglobal }}(t)$. This design variable composes the vector $x$ of this second LP optimization.

The objective function is similar to the previous case, but this time, the algorithm search for the minimum capacity value that since the first day of the year is capable of fulfilling the requirements of the whole year. This is represented as

$$
\underset{C_{\text {batglobal }}}{\min } C_{\text {batglobal }_{\text {glo }}}(1) \text {. }
$$

The constraints, in this case, are the following: First, the optimal capacity value for every day of the year $\left(C_{\text {bat }_{\text {global }}}(t)\right)$ must be equal or greater than the capacity need obtained in the previous optimization for every day $\left(C_{\text {bat }}(t)\right)$; and second, the capacity decay according to the energy throughput between two consecutive days must be considered. The equations that model these criteria are presented in (20) and (21), and are included in

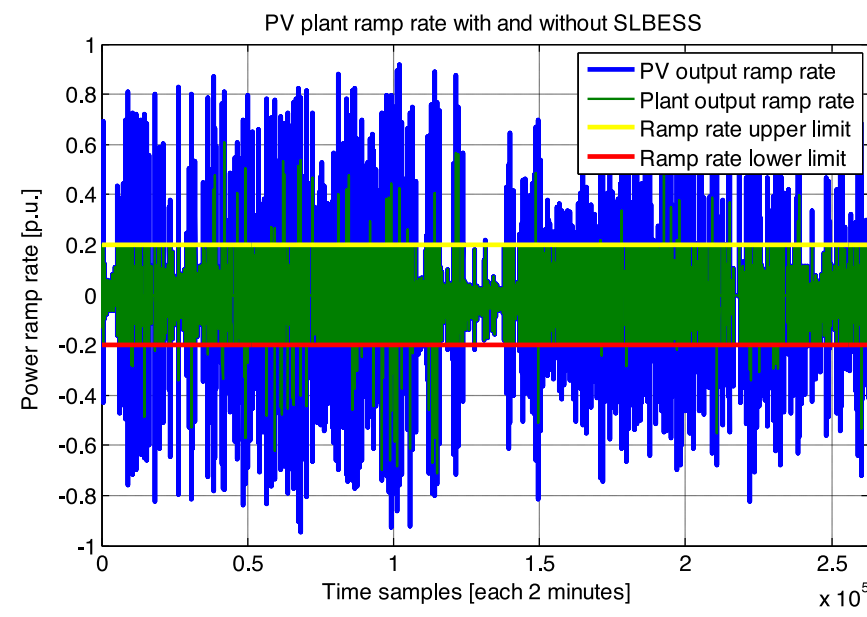

Fig. 4. Yearly output power ramp-rate analysis: The output power ramp rate of the PV system and of the plant when the MLSERRC algorithm is used.

the matrixes $A, A_{\mathrm{eq}}$, and vectors, $b_{\mathrm{eq}}$, respectively,

$$
\begin{aligned}
& -C_{\text {bat }_{\text {global }}}(t) \leq-C_{\text {bat }}(t) \\
& C_{\text {bat }_{\text {global }}}(t)-C_{\text {bat }_{\text {global }}}(t-\Delta t)=Z \cdot \operatorname{Sum}_{\text {disch }}(t)
\end{aligned}
$$

The initial condition of (21) is calculated as

$$
\mathrm{SOH}_{\text {min }} \cdot C_{\text {batglobal }}(1)-C_{\text {batglobal }}(365)=0 .
$$

This initial condition ensures that the battery capacity decay during the whole year will not be greater than the maximum capacity decay allowed for the SLBESS. In other words, (22) ensures that the SL battery retirement $\mathrm{SOH}$ is not reached prior to completing, at least, one year of operation. The second optimization process is also developed in MATLAB.

\section{OPTIMIZATION RESULTS AND DISCUSSION}

At first, an analysis of the ramp rates for the available oneyear measurement data presents the initial conditions of the PV power plant prior to the use of the SLBESS for the variability smoothing service. As mentioned in Section II, the ramp-rate limit that the plant must provide is $10 \% / \mathrm{min}$. (or, based on the available 2 min. sample measurements, 20\%/2min.).

Fig. 4 presents the ramp rate of the PV output before using the SLBESS as well as the results when using the smoothing application as a result of the global optimization. Fig. 5 presents a statistical insight regarding the frequency distribution of different ramp rates over the one-year available data (the inlet zooms the lower fraction of the histogram, with frequencies below 3000 samples over one year).

Using the optimization program defined in Section III, the daily optimal values of the battery capacity for the variability smoothing application were obtained. These values are plotted in Fig. 6 showing that there are different values required for the battery capacity depending on the day of the year. For achieving the ramp-rate constraints defined in Section II, the nominal capacity of the SLBESS is obtained based on the daily optimal values and battery energy charge/discharge profiles. This process is illustrated in Fig. 6. The initial optimal value of the $C_{\text {ref }}$ 


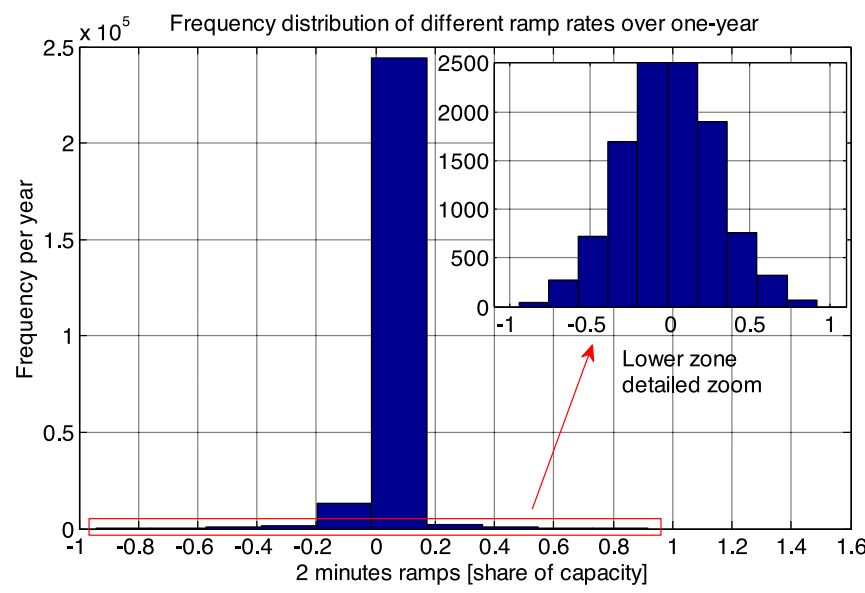

Fig. 5. Yearly output power ramp-rate analysis. The distribution diagram of power ramp rates of different magnitudes over the entire year.

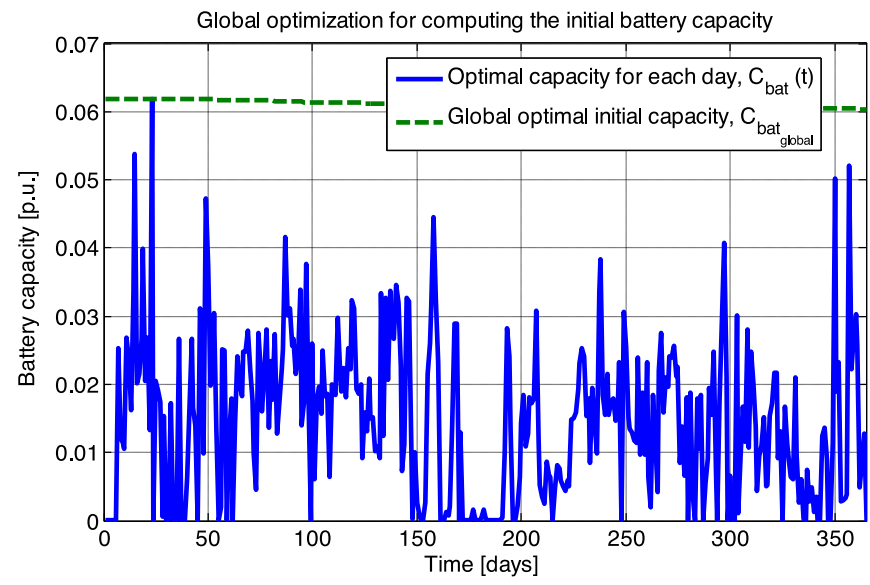

Fig. 6. Daily optimal values for $C_{\mathrm{bat}}$ and the rating of the battery according to capacity decay.

was obtained as the minimum value that provides the necessary capacity for the battery to achieve the power smoothing throughout the entire year, considering the capacity fade characteristics and the daily optimal value constraints. This figure presents the decay of the battery starting from the initial value during one year of operation.

The solution of the optimization problem, representing the optimal operation case, was used to simulate the operation using the MLSERRC algorithm presented in Section III for assessing the real operation and validity of the obtained result.

For testing the performance of the proposed algorithm and to validate the results obtained by utilizing the optimization program, the RRC assessment proposed by APER in [8] was used. As stated in Section II, a curtailment penalty will be applied to the plant if the RRC is less than $98.5 \%$ during a week.

The PV production data used to validate the RRC were the same than the data used for the optimization of the SLBESS sizing. Although the use of different training and validation data is generally advisable, no additional real data were available in this case for validation purposes. Nevertheless, the operation of one whole year was evaluated, as it is considered that the

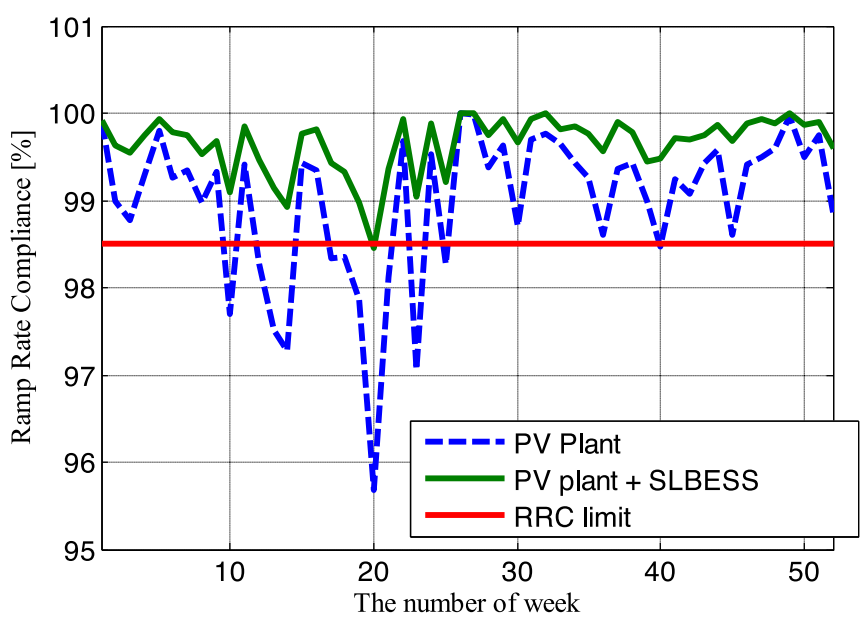

Fig. 7. RRC for the PV plant when the plant is directly connected to the grid and when the SLBESS is used for the output power smoothing.

seasonal changes have larger effect on PV plan output power variability than year-to-year changes. Thereby, an SLBESS capable of fulfilling the RRC criterion over one-year operation should also be capable of respecting the ramp-rate limits in the upcoming years. Fig. 7 presents the RRC computed for the plant as stated in (2). The RRC is computed for each week of the one-year interval for two cases: the initial PV plant generating power according to the variable nature of the solar irradiance and the second case corresponding to the plant operating with the SLBESS. The SLBESS is rated by utilizing the optimization program. Although the optimization is implemented considering perfectly known energy production conditions (the optimal case), for evaluating the performance of the SLBESS calculated on a realistic working scenario, the algorithm used was the MLSERRC, as described in Section III.

From Fig. 7 it is seen that the RRC limits are not violated and the plant operates without penalties.

As the optimization program considers the optimal operation (a perfectly predicted scenario) the resulting capacity of the battery (0.0612 p.u.) must be checked according to the defined MLSERRC operation algorithm, for testing its evolution when battery system is ageing (see Fig. 8) and assess the RRC as defined in (2).

Fig. 8 presents the operation of the SLBESS during one year, by using the initial capacity obtained from the optimization program when using the MLSERRC algorithm for the operation of SLBESS. The battery stored energy level is kept between the limits imposed by the battery energy management, defined as $\mathrm{SOC}_{\min }(20 \%)$ and $\mathrm{SOC}_{\max }(80 \%)$. Another aspect noticeable in this operation scenario is the battery's capacity decay over time, as a result of the battery operation.

Results from Fig. 7 suggested that the global optimum sizing selected is significantly oversized for the biggest part of the year. However, these results only prove that the total energy throughput on each day of the year is normally smaller than the optimal capacity determined for the SLBESS. In contrast, Fig. 8 shows that the lower and upper SOC operation limits are frequently reached. These two figures together prove that a typical 


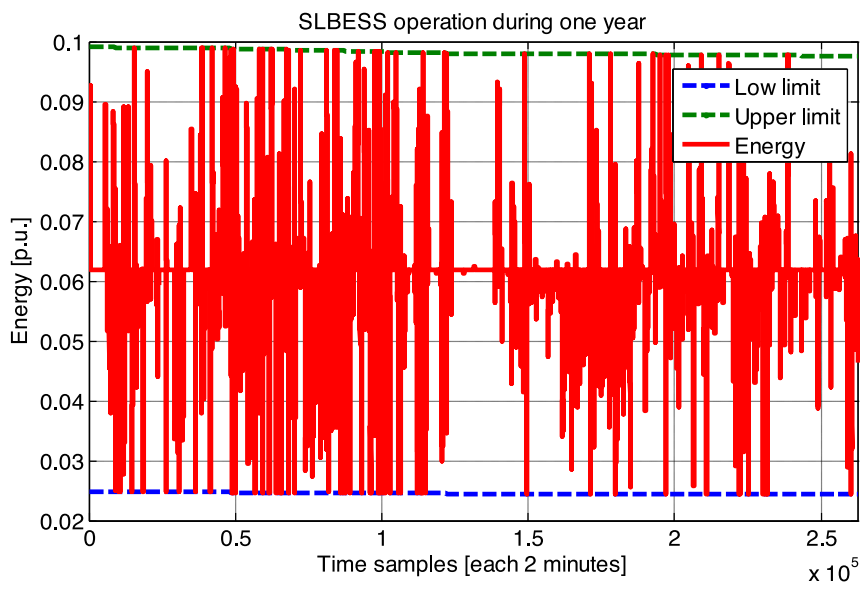

Fig. 8. SLBESS energy status during one year when using the MLSERRC algorithm for variability smoothing.

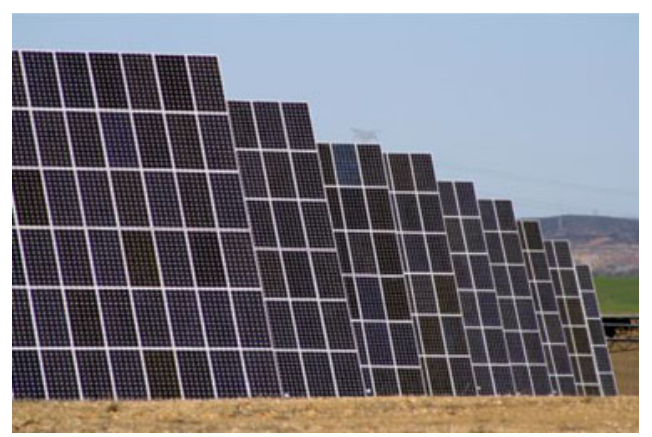

Fig. 9. Casaquemada PV plant (Solucar Platform, Sanlucar la Mayor, Seville, Spain).

day with a PV output power variability event forces the battery to operate between the SOC limits established (20\%-80\% SOC operation). In addition, the days recording several consecutive variability events (large energy demand) pushed the optimization to a larger SLBESS sizing. Considering the two issues mentioned here, it can be concluded that the SLBESS calculated is not oversized for the biggest part of the year, and that although only few days of the year require a large energy throughput, the size of the SLBESS is correctly adjusted to leverage the defined SOC range during the biggest part of the year.

\section{BATtery Test Profile Definition}

The ultimate goal of the study performed was to obtain realistic cycling patterns for laboratory SL battery testing.

A real PV power plant is considered as a case study for the evaluation of the results obtained with the presented sizing methodology. The considered PV power plant is the Casaquemada PV plant, located at the Solucar Platform in Sanlucar la Mayor (Seville, Spain) and owned by Abengoa Solar, Fig. 9. Composed of 135 two-axis crystalline silicon technology trackers and 18 high concentration technology trackers, it can provide up to 1.9 MW rated power output [32].

The optimal SLBESS sizing calculated for a PV plant with such characteristics results into a $235.22-\mathrm{kWh}$ battery system. The configuration of the SLBESS has been calculated
TABLE II

Characteristics OF THE PROPOSED SLBESS CONFIGURATION

\begin{tabular}{lc}
\hline \hline Characteristics & Value \\
\hline Output power of the PV plant & $1.9 \mathrm{MW}$ \\
Installed BP capacity & $235.22 \mathrm{~kW}$ \\
Output voltage of each battery rack & $690 \mathrm{~V}(\mathrm{~min})$. \\
Nominal cell voltage & $3.65 \mathrm{~V}$ \\
Minimum cell voltage & $3 \mathrm{~V}$ \\
Cells configuration on each rack & $230 \mathrm{~S} 1 \mathrm{P}$ \\
Capacity of 1 rack & $16 \mathrm{Ah}(1 \mathrm{cell})$ \\
Racks in parallel & 22 \\
\hline \hline
\end{tabular}

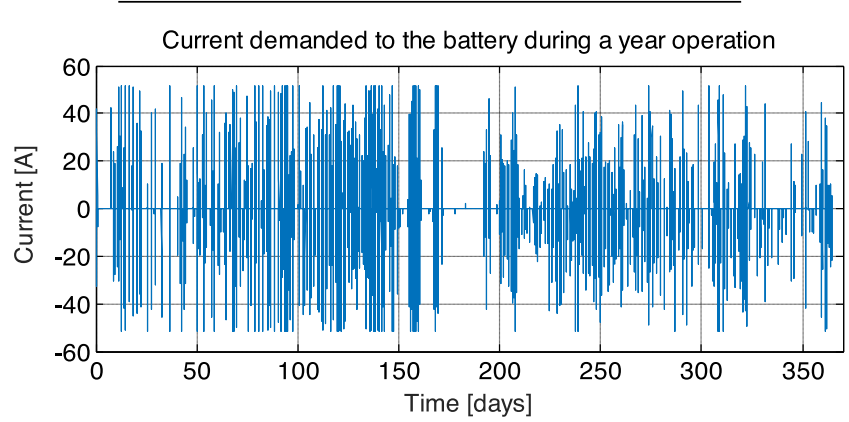

State of Charge profile of the battery during a year operation

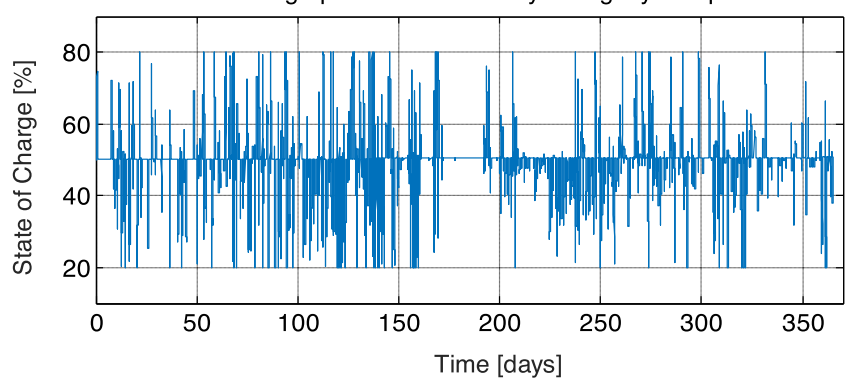

Fig. 10. One-year current operation profile demanded to each SL cell of the SLBESS.

considering a nominal voltage output of $690 \mathrm{~V}$ for the SLBESS, and 16-Ah current capacity for the SL batteries used in this application- $80 \%$ of the nominal capacity after the automotive retirement.

The resultant SLBESS calculated is composed of 22 battery racks connected in parallel, Table II Each rack consists of 230 SL cells connected in series. This configuration leads to a total SLBESS capacity of $242.88 \mathrm{kWh}$ and $690 \mathrm{~V}$ nominal output voltage. Although it is slightly larger than the optimal capacity calculated, it was readapted in order to fulfill the limitations of the testing equipment available.

The resultant current profile demanded to each cell of the battery system is calculated from the total power demanded to the SLBESS, as it can be observed in Fig. 10. This current profile will be used for experimental testing of the SL batteries, which will enable the analysis of SL battery performance capabilities and their ageing evolution after the automotive first life retirement. These results are out of this paper scope.

\section{CONCLUSION}

This paper presents a sizing approach for an SLBESS providing variability smoothing service of $\mathrm{PV}$ power plants. The choice 
of SL batteries for this service represents a cost-effective alternative solution for the use of new storage systems. However, the applied optimization strategy is applicable for any kind of BESS.

By using the proposed optimization method, and based on real power generation data taken from a PV plant, the optimal ratings for an SLBESS are calculated. In addition, the study uses a new variability smoothing algorithm for emulating the operation conditions of the SLBESS during an entire year of operation.

Furthermore, the analysis performed allows obtaining power profiles and cycling patterns representative to the application considered, building a basis for experimental laboratory testing of SL batteries.

As the last step of the presented study, the obtained battery demand power profiles will further be used for SL battery testing. It is foreseen that the SL battery analysis will shed some light over the performance capabilities of such batteries and it will enable evaluating their ageing behavior when used for providing PV power variability smoothing.

\section{REFERENCES}

[1] S. Chowdhury and P. Crossley, Microgrids and Active Distribution Networks. Institution of Engineering and Technology, 2009.

[2] S. Vazquez, S. M. Lukic, E. Galvan, L. G. Franquelo, and J. M. Carrasco, "Energy storage systems for transport and grid applications," IEEE Trans. Ind. Electron., vol. 57, no. 12, pp. 3881-3895, Dec. 2010.

[3] C. Koch-Ciobotaru et al., "Second life battery energy storage system for enhancing renewable energy grid integration," in Proc. IEEE Energy Convers. Congr. Expo., 2015, pp. 78-84.

[4] Entso-E, "Network code for requirements for grid connection applicable to all generators," p. 81, Jun. 2013.

[5] C. Gavriluta, I. Candela, J. Rocabert, I. Etxeberria-Otadui, and P. Rodriguez, "Storage system requirements for grid supporting PVpower plants," in Proc. IEEE Energy Convers. Congr. Expo., 2014, pp. 5323-5330.

[6] J. Marcos, O. Storkël, L. Marroyo, M. Garcia, and E. Lorenzo, "Storage requirements for PV power ramp-rate control," Solar Energy, vol. 99, pp. 28-35, Jan. 2014.

[7] G. Wang, M. Ciobotaru, and V. G. Agelidis, "Power smoothing of large solar PV plant using hybrid energy storage," IEEE Trans. Sustain. Energy, vol. 5, no. 3. pp. 834-842, Jul. 2014.

[8] Asociación de Productores de Energía Renovable (APER), "PREPA minimum technical requirements compliance procedure proposal," 2013.

[9] A. Etxeberria, I. Vechiu, H. Camblong, and J.-M. Vinassa, "Hybrid energy storage systems for renewable energy sources integration in microgrids: A review," in Proc. IPEC Conf., 2010, pp. 532-537.

[10] A. Arabali, M. Ghofrani, M. Etezadi-Amoli, and M. S. Fadali, "Stochastic performance assessment and sizing for a hybrid power system of solar/wind/energy storage," IEEE Trans. Sustain. Energy, vol. 5, no. 2, pp. 363-371, Apr. 2014.

[11] X. Li, D. Hui, and X. Lai, "Battery energy storage station (BESS)based smoothing control of photovoltaic (PV) and wind power generation fluctuations," IEEE Trans. Sustain. Energy, vol. 4, no. 2, pp. 464-473, Apr. 2013.

[12] H. Beltran, M. Swierczynski, A. Luna, G. Vazquez, and E. Belenguer, "Photovoltaic plants generation improvement using Li-ion batteries as energy buffer," in Proc. IEEE Int. Symp. Ind. Electron., 2011, pp. 2063-2069.

[13] H. Beltran, E. Perez, N. Aparicio, and P. Rodriguez, "Daily solar energy estimation for minimizing energy storage requirements in PV power plants," IEEE Trans. Sustain. Energy, vol. 4, no. 2. pp. 474-481, Apr. 2013.

[14] M. Gitizadeh and H. Fakharzadegan, "Battery capacity determination with respect to optimized energy dispatch schedule in grid-connected photovoltaic (PV) systems," Energy, vol. 65, pp. 665-674, Feb. 2014.
[15] Y. Ru, J. Kleissl, and S. Martinez, "Storage size determination for gridconnected photovoltaic systems," IEEE Trans. Sustain. Energy, vol. 4, no. 1, pp. 68-81, Jan. 2013.

[16] S. Hashemi, J. Ostergaard, and G. Yang, "A scenario-based approach for energy storage capacity determination in LV grids with high PV penetration," IEEE Trans. Smart Grid, vol. 5, no. 3. pp. 1514-1522, May 2014.

[17] M. Z. Daud, A. Mohamed, and M. A. Hannan, "An improved control method of battery energy storage system for hourly dispatch of photovoltaic power sources," Energy Convers. Manage., vol. 73, pp. 256-270, Sep. 2013.

[18] A. Saez-de-Ibarra, A. Milo, H. Gaztanaga, V. Debusschere, and S. Bacha, "Co-optimization of storage system sizing and control strategy for intelligent photovoltaic power plants market integration," IEEE Trans. Sustain. Energy, 2016, to be published.

[19] Ik4-Ikerlan, "Batteries2020," Batteries 2020 official web page. [Online] Available: http://www.batteries2020.eu/

[20] A. Keeli and R. K. Sharma, "Optimal use of second life battery for peak load management and improving the life of the battery," in Proc. IEEE Int. Elect. Veh. Conf., 2012, pp. 1-6.

[21] C. Davis and B. Schultz, "Second life hybrid vehicle batteries used in solar backup," in Proc. IEEE Green Technol. Conf., 2012, p. 1.

[22] G. Lacey, G. Putrus, and A. Salim, "The use of second life electric vehicle batteries for grid support," in Proc. IEEE EUROCON, Jul., 2013, pp. $1255-1261$.

[23] J. Neubauer and A. Pesaran, "The ability of battery second use strategies to impact plug-in electric vehicle prices and serve utility energy storage applications," J. Power Sources, vol. 196, no. 23, pp. 10351-10358, 2011.

[24] USABC, "USABC electric vehicle battery test procedures manual, revision 2," 1996.

[25] S. Saxena, C. Le Floch, J. MacDonald, and S. Moura, "Quantifying EV battery end-of-life through analysis of travel needs with vehicle powertrain models," J. Power Sources, vol. 282, pp. 265-276, May 2015.

[26] V. Gevorgian and S. Booth, "Review of PREPA technical requirements for interconnecting wind and solar generation review of PREPA technical requirements for interconnecting wind and solar generation," National Renewable Energy Laboratory, Golden, CO, USA, Tech. Rep. NREL/TP5D00-57089, Nov. 2013

[27] B. R. Ke, T. T. Ku, Y. L. Ke, C. Y. Chuang, and H. Z. Chen, "Sizing the battery energy storage system on a university campus with prediction of load and photovoltaic generation," IEEE Trans. Ind. Appl., vol. 52, no. 2. pp. 1136-1147, Mar./Apr. 2016

[28] Y. Yang, E. Koutroulis, A. Sangwongwanich, and F. Blaabjerg, "Minimizing the levelized cost of energy in single-phase photovoltaic systems with an absolute active power control," in Proc. IEEE Energy Convers. Congr Expo., 2015, pp. 28-34.

[29] L. Meng et al., "Flexible system integration and advanced hierarchical control architectures in the microgrid research laboratory of aalborg university," IEEE Trans. Ind. Appl., vol. 52, no. 2. pp. 1736-1749, Mar./Apr. 2016.

[30] Y. Riffonneau, S. Bacha, F. Barruel, and S. Ploix, "Optimal power flow management for grid connected PV systems with batteries," IEEE Trans. Sustain. Energy, vol. 2, no. 3. pp. 309-320, Jul. 2011.

[31] ISO, "ISO/DIS 12405-2 Electrically propelled road vehicles-Test specification for lithium-Ion traction battery systems-Part 2: High energy applications," 2011.

[32] Abengoa Solar S.A., "Nuestros productos :: Plantas solares," [Online]. Available: http://www.abengoasolar.com/web/es/nuestros_productos/plantas_solares/. [Accessed: 30-Dec-2015].

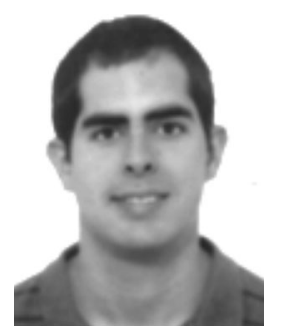

Andoni Saez-de-Ibarra received the B.Sc. and M.Sc. degrees in electronics from the University of Mondragón, Mondragón, Spain, in 2009 and 2012, respectively, and the M.Sc. degree in electrical engineering from Grenoble Institute of Technology, Grenoble, France, in 2012. He is currently working toward the Ph.D. degree in Grenoble Electrical Engineering Laboratory, University of Grenoble, Grenoble, in collaboration with IK4-IKERLAN Technology Research Centre, Mondragón.

His research interests include the energy management and market integration of renewable energies associated with energy storage systems and electric transport. 


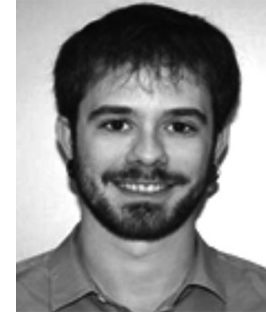

Egoitz Martinez-Laserna was born in VitoriaGasteiz, Spain, in 1989. He received the M.Sc. degree in electronic engineering from the University of Mondragón, Mondragón, Spain, in 2013. He joined the Energy Business Unit of IK4-IKERLAN Technological Research Center, Mondragón, in 2013, where he is currently working toward the Ph.D. degree in IK4-IKERLAN focused on second life battery performance, sizing, and integration.

His research interests include electrochemical energy, and energy management.

energy storage systems, electric vehicles, renewable

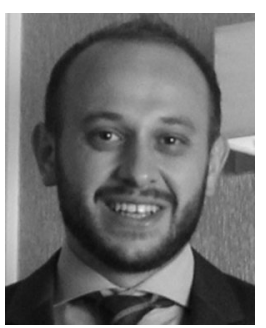

Daniel-Ioan Stroe received the Dipl.-Ing. degree in automatics from "Transilvania" University of Brasov, Brasov, Romania, in 2008, and the M.Sc. degree in wind power systems and the Ph.D. degree in lifetime modeling of lithium-ion batteries from Aalborg University, Aalborg, Denmark, in 2010 and 2014, respectively.

Since 2010, he has been an Assistant Professor in the Department of Energy Technology, Aalborg University. He was a Visiting Researcher with RWTH Aachen, Aachen, Germany, in 2013. He has co-authored more than 40 journal and conference papers. His current research interests include the area of energy storage systems for grid and e-mobility, lithium-based batteries testing and modeling, and lifetime estimation of lithiumion batteries.

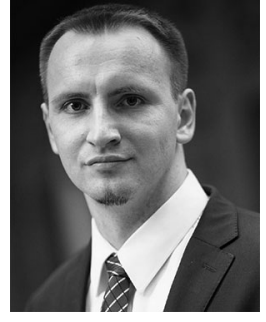

Maciej Swierczynski received the B.Tech. and M.Tech. degrees in computer engineering for industrial applications from the AGH University of Science and Technology, Cracow, Poland, in 2005 and 2007. respectively, and the M.Tech. and Ph.D. degrees in power electronics and drives from Aalborg University, Aalborg, Denmark, in 2009 and 2012, respectively, with Ph.D. thesis: "Lithium-ion battery energy storage system for augmented wind power plants."

$\mathrm{He}$ is currently an Associate Professor with Aalborg University. His research interest includes energy storage technologies for wind and EV applications, battery testing, modeling, and lifetime analyses.

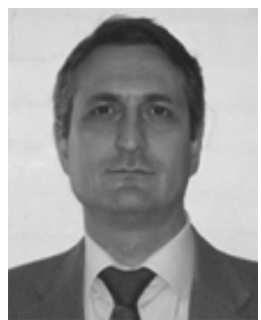

Pedro Rodriguez (F'13) received the M.Sc. and $\mathrm{Ph} . \mathrm{D}$. degrees in electrical engineering from the Technical University of Catalonia (UPC), Barcelona, Spain, in 1994 and 2004, respectively.

He was a Postdoctoral Researcher at the Center for Power Electronics Systems, Virginia Tech, Blacksburg, VA, USA, in 2005, and with the Department of Energy Technology, Aalborg University (AAU), Aalborg, Denmark, in 2006. He joined the faculty of UPC as an Assistant Professor in 1990, where he became the Director of the Department of Electrical Engineering, Research Center on Renewable Electrical Energy Systems, Barcelona. He is currently a part time Professor with UPC. He was also a Visiting Professor at AAU from 2007 to 2011, and a Co-Supervisor of the Vestas Power Program. In 2011, he joined Abengoa, Seville, Spain, where he is currently the Director of Technology on Power Systems and Power Electronics. He has coauthored one book, more than 70 papers in ISI technical journals and around 250 papers in conference proceedings. He is the holder of 12 licensed patents. His current research interests include distributed power systems, flexible transmission systems, and power conversion.

Dr. Rodriguez received the Best Technical Letter Award 2012 and the Second Best Paper Award 2012 in the IEEE TRANSACTIONS ON POWER ELECTRONICS and the Second Paper Paper Award 2014 in the IEEE Journal OF EMERGING AND SEleCted Topics in Power Electronics. He is an Associate Editor of the IEEE TRANSACTION ON POWER EleCtronics. He was the Vice Chair of the Sustainability and Renewable Energy Committee of the IEEE Industry Application Society. 